\title{
Simple Tool for Aircraft Noise-Reduction Route Design
}

\author{
Jinhua $\mathrm{Li}^{*} \quad$ Neil Chen ${ }^{\dagger} \quad$ Hok K. Ng ${ }^{\ddagger} \quad$ Banavar Sridhar $\S$
}

\begin{abstract}
The design of arrival and departure routes from an airport has to balance the conflicting requirements of fuel efficiency, airport capacity utilization and community emission and noise considerations. The commonly used tools for aircraft noise assessment are the FAA's Integrated Noise Model (INM) and Aviation Environmental Design Tool (AEDT). These tools are suitable to generate precise noise contours. However, they are harder to use with other tools for route design optimization involving evaluation of a large number of aircraft trajectories. A simplified aircraft noise computation tool, named AIRNOISE, is developed for preliminary aircraft noise-reduction route design in this paper. AIRNOISE computes aircraft noise based on the same SAE-AIR-1845 procedures used by INM and AEDT. AIRNOISE does not consider components related to terrain and atmosphere adjustments. As a result, it is not only computationally efficient but also flexible to use for customized aircraft profiles. The aircraft noise results are compared with the FAA's AEDT2b and show that the level of accuracy achieved by AIRNOISE can be used to reduce the number of route design options to a small number from a large pool for subsequent accurate analysis by INM.
\end{abstract}

\section{Introduction}

NASA is developing air traffic management tools to design safe and efficient aircraft routes while balancing emissions and environmental considerations. 1.2]3 The design of arrival and departure routes from an airport has to balance the conflicting requirements of fuel efficiency, airport capacity utilization and community emission and noise considerations. INM (Integrated Noise Model) is a software used by the FAA for airport noise assessment and regulation. Emission and Dispersion Modeling System (EDMS) is used to assess airport air quality by modeling surface emissions and dispersion. The FAA is leading the development of the Aviation Environment Design Tool (AEDT) that integrates both INM and EDMS into an integrated tool to study the environmental consequence of aviation. These tools are suitable to generate precise noise contours. However, they are harder to use with other tools for route design optimization involving evaluation of a large number of aircraft trajectories.

Development of environmentally friendly aircraft routes and operations require models of aircraft performance, emissions and noise. The Base of Aircraft Data (BADA) is widely used for aircraft performance models and the Boeing Fuel Flow Method (BFFM) is used for computing engine emissions of $C O, H C$, $\mathrm{NO}_{\mathrm{X}}, \mathrm{CO}_{2}, \mathrm{H}_{2} \mathrm{O}$ and $\mathrm{SO}_{x}$. For aircraft-induced contrail modeling, both German Aerospace Center (DLR)'s Contrail Cirrus Prediction Tool (CoCiP) $)^{4}$ and NASA's Aviation Contrail Simulation Model (ACSM) ${ }^{\sqrt{5}}$ are among the early attempts to model the full life-cycle of aviation-induced linear contrails and compute the corresponding radiative forcings for global warming impact.

Figure 1 shows a common flow chart to design the optimal aircraft routes to minimize total fuel consumption, emissions, and noise. There is other research related to the design of fuel optimal aircraft routes. Aircraft engine emitted carbon dioxide $\left(\mathrm{CO}_{2}\right)$ can be easily incorporated into the cost function because it is directly proportional to fuel consumption. Aircraft noise and its impact on residents in the vicinity of airports have been well studied $\underline{6] 7}$ Research has focused on aircraft noise acoustic modeling and aircraft noise impact assessment and a few studies have focused on designing aircraft routes for airport noise impact reduction $[\sqrt[8]{ }$ However, other work attempted to minimize aviation-induced climate impact. Examples include

\footnotetext{
*Research Engineer, Stinger Ghaffarian Technologies, email: jinhua.li@nasa.gov

$\dagger$ Research Aerospace Engineer, Aviation Systems Division, NASA Ames Research Center

${ }^{\ddagger}$ Research Scientist, University of California, Santa Cruz

$\S$ Senior Scientist, NASA Ames Research Center, AIAA fellow
} 
designing trans-Atlantic routes to reduce the climate impact due to aircraft greenhouse gas emissions and contrails, $\frac{9]}{,}$ and evaluating ozone impact due to aviation nitrogen oxide $\left(N O_{x}\right)$ emissions $\left[\frac{10}{10}\right.$

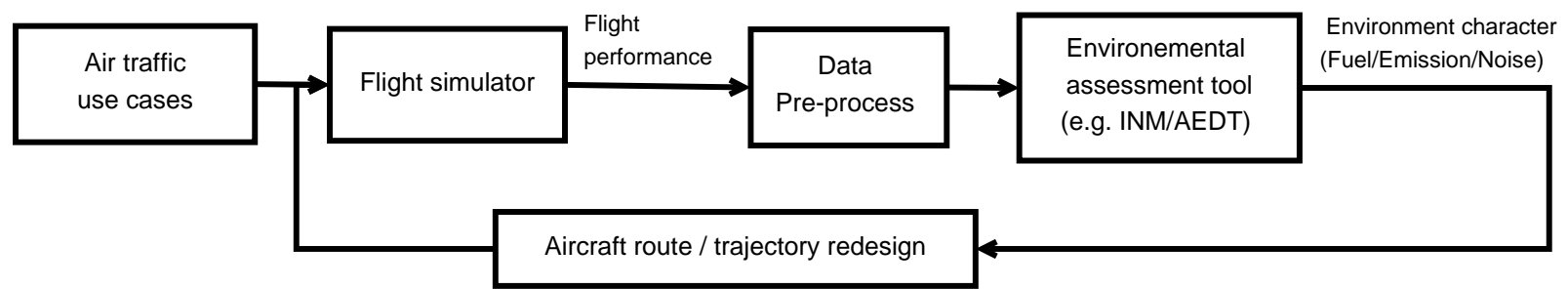

Figure 1: Flow chart of aircraft route and trajectory design and assessment

Note that in Fig. 1, software such as INM and AEDT are included in the internal parts of the design loop. However, the standalone nature and restrictive format of input aircraft profiles make it difficult to integrate INM and AEDT with other optimization software.

Figure 2 shows an alternative design flow chart, in which simplified environmental computation modules are first developed and then integrated into the flight simulation software. The benefits include: (1) improved computational efficiency by only reserving the core computation components for the closed-loop iterative computation; (2) access to internal components and intermediate results and acceptance of customized aircraft profiles (including airspeed and engine thrust) inputs; and (3) pre-screening candidate aircraft routes to reduce the scope of the search space. Finally, designed routes with aircraft performance data are fed into AEDT and/or INM for environment impact assessment. Aircraft performance, emission, and contrail computation modules have been developed and integrated into NASA's fast-time flight simulation software, Future ATM Concepts Evaluation Tool (FACET), in our previous work. 2] This paper focuses on aircraft noise. The aircraft noise computation method is the standard SAE-AIR-1845 procedures used by INM and AEDT 11 In summary, a simplified noise computation tool based on SAE-AIR-1845 procedures without considering components related to terrain and atmosphere adjustments is developed in this paper. The noise computation tool is integrated with FACET or other flight simulation software for designing noise-reducing aircraft routes.

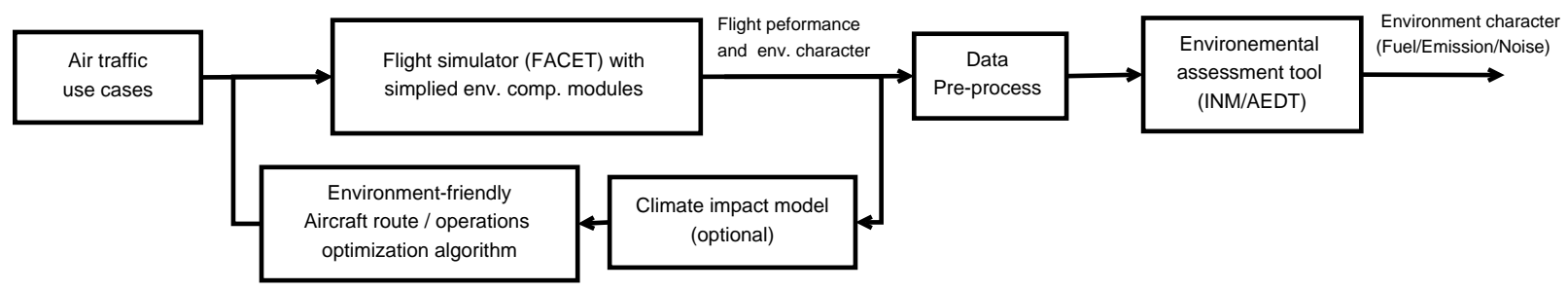

Figure 2: Flow chart of environmentally friendly aircraft route and operation design and assessment

The rest of this paper is organized as follows: Section II presents the simplified SAE-AIR-1845 noise computation method. Section III compares the results of the simplified model with those of the FAA's aviation environment software AEDT2b. Section IV provides some concluding remarks and further extension of the paper.

\section{Noise Computation Method}

Average Day-and-Night Sound Level (DNL) is the most commonly used aircraft noise metric and is used for US Federal noise standards. For example, 65decibels (dB) DNL is the federal significance threshold for aircraft noise exposure (refer to the FAA Order 1050.1E). Residences that are exposed to 65dB DNL and above may qualify to receive federal assistance for noise insulation or other compensation. DNL is calculated by weighted summation of Sound Exposure Level (SEL) of individual aircraft operation over a 24-hour period. The weighting is used to account for lower background noise. The SAE-AIR-1845 noise computation method used in this study describes procedures for calculating SEL at ground locations $\frac{11}{11}$ By SAE-AIR1845 procedures, SEL resulting from an aircraft is computed by adding the base noise of the specific aircraft 
engine type from Noise-Power-Distance (NPD) data tables plus some adjustment terms, $\frac{12}{12}$ as follows:

$$
L_{a e}=L_{a e}(P, d)+A D J_{N F}+A D J_{D U R}-A D J_{L A}+A D J_{D I R}
$$

NPD base noise values $L_{a e}(P, d)$ are FAA certified which assume straight overhead flight at a constant speed of 160knots. Slant distance $d$ is the perpendicular distance from observer to the aircraft route which consists of a sequence of linear segments. $P$ is corrected engine net thrust.

There is a set of adjustments to account for variations of the flight relative to the observer. The noise fraction adjustment $\left(A D J_{N F}\right)$ is required because the length of each flight segment is finite which is opposite to the infinite-length aircraft route assumption used when measuring NPD base noise. A noise duration adjustment term $\left(A D J_{D U R}\right)$ is used to account for aircraft speed variation. This adjustment becomes nonzero after $160 \mathrm{knots}$. The noise lateral attenuation adjustment term $\left(A D J_{L A}\right)$ is applied when the observer is not directly under the aircraft route as noise would gradually decrease as the observer moves away from aircraft route. The noise ground-based directivity adjustment term $\left(A D J_{D I R}\right)$ deals with special cases when the observer is behind the aircraft during the takeoff ground roll.

Figure 3 shows a flow chart describing the process of the noise computation model, named AIRNOISE. The equations for the adjustment terms in Eqn. (10) from the INM technical manual ${ }^{12}$ are given in the appendix. An accumulated SEL for multiple aircraft route segments is calculated by:

$$
L_{a e, f l t}=10 \log _{10} E_{a e}, E_{a e}=\sum_{i=1}^{N_{s e g}} 10^{\frac{L_{a e}(i)}{10}}
$$

where $L_{a e}(i)$ is the SEL of the $i$ th aircraft route segment calculated using Eqn. (11) and $N_{\text {seg }}$ is the total number of aircraft route segments.

Finally, the DNL for all aircraft activities over a 24-hour period is computed by:

$$
L_{d n}=\sum_{f l t_{i} \in d a y} 10^{\frac{L_{a e, f l t_{i}}}{10}}+\sum_{f l t_{j} \in \text { night }} 10^{\frac{L_{a e, f l t_{j}+10}}{10}}-49.4
$$

where daytime operation is defined from 0700 to 2200 and nighttime operation is defined from 2200 to 0700 local time. So all nighttime flight operations are penalized by 10db by the definition of DNL.

Since AIRNOISE is a simplified model of INM, the system flow chart is essentially the same by comparing Fig. 3 with Fig. 3-1 from the INM7.0 Technical Manual 12 Differences are attributed to some other adjustment terms for the atmosphere and terrain adjustments that were not included in AIRNOISE. Those terms are generally less important compared with the terms that are considered in Eqn. (1).

Equation (11) is only applied for exposure-based sound exposure level computation. Another commonlyused metric is maximum-based sound level, which is computed by:

$$
\begin{gathered}
L_{a s m x}=L_{a s m x}(P, d)-A D J_{L A}+A D J_{D I R} \\
\left.L_{a s m x}=\max _{i=1, \ldots, N_{s e g}}\left(L_{a s m x}(i)\right)\right)
\end{gathered}
$$

Comparing Eqns. (11) and (4), the maximum-based sound level does not require duration adjustment and fraction adjustment.

In the rest of this section, key flow chart components in Fig. 3 are discussed. First, Figure 4 displays NPD data for a few Boeing and Airbus commercial aircraft with a slant range distance setting at $d=1000 \mathrm{ft}$ with various engine-power settings for both standard departure and arrival profiles. Some observations from Fig. 目are: (1) There are clear separations between newer models and older models, in which NPD data for newer models are pushed toward the lower right corner of the plots (i.e. newer models generate lesser noise even with greater engine-power). This exemplifies the manufacturer's progress on engine noise reduction technology while boosting engine power; (2) Arrival aircraft have less sound exposure variation and absolute sound exposure within operating engine-power range than departure aircraft of the same model. For example, sound exposure variance is $10.3 \mathrm{db}$ for departure and $2.5 \mathrm{db}$ for arrival for the Boeing $787 R$. Sound exposure variance is $9.1 \mathrm{db}$ for departure and $1.3 \mathrm{db}$ for arrival for the Airbus A380. This indicates that departure aircraft sound exposure is more sensitive to engine-power. 


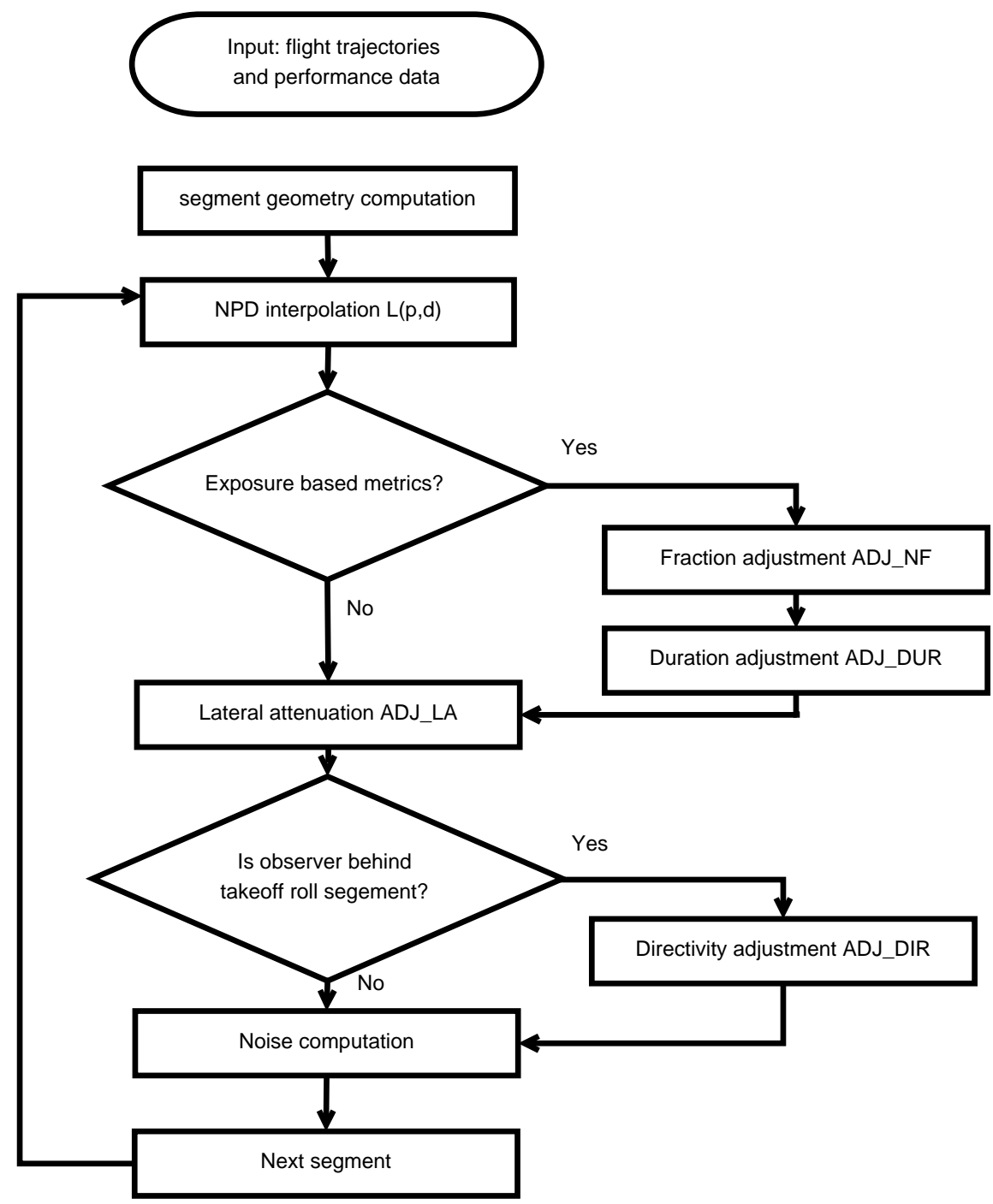

Figure 3: Flow chart of AIRNOISE model

Second, it is a prerequisite to compute geometric parameters based on aircraft route segment and observer positions. Consider a simple case for illustration. Given a departure aircraft route segment of an Airbus A340-211, where aircraft performance ([Ground distance(ft) (or latitude and longitude), Altitude(ft), Speed(knots), Thrust(lb-force)]) are $P 1=[5893.2,741.9,138.9,25936.9]$ at the start point and $P 2=[6635.1,1100.4,139.1,25976.4]$ at the end point. There are 3 cases based on relative position between observer and aircraft route segment: (a) Observer is aside aircraft route segment; (b) Observer is behind aircraft route segment; and (c) Observer is ahead aircraft route segment. Figure 5]shows geometric parameters including $S L R_{s}$ (slant range (closest) distance to the flight segment), $S L R_{p}$ (slant range (closest) distance to the flight path), and $\beta$ (elevation angle) as well as computed exposure-based sound level using Eqn. (11) and maximum sound level using Eqn. (4) for each case with NPD data tables for the Airbus A340-211. Note that sound exposure level $L_{a e}$ is almost always greater than maximum sound level $L_{a s m x}$ by their definitions, where maximum sound level is the maximum instantaneous sound pressure and sound exposure level is the sum of sound energy (i.e. square of sound pressure) over the duration of a noise event.

\section{Simulation Results}

An arrival route and a departure aircraft route for a Boeing 737-300 at San Francisco International Airport are simulated using the FAA's AEDT2b. Their flight profiles are exported as input to AIRNOISE. 


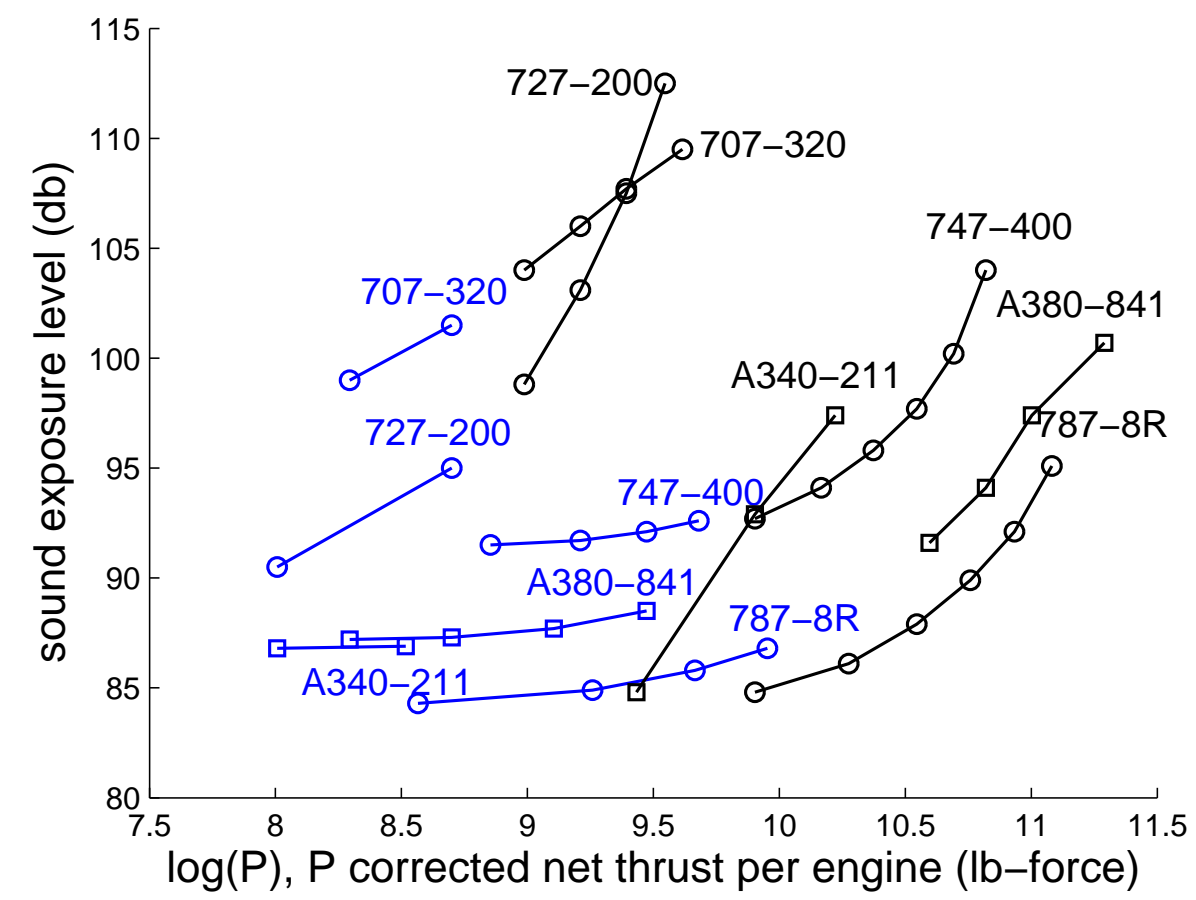

Figure 4: NPD data of selected Boeing 700-series and Airbus 300-series aircraft at 1000ft slant range distance for standard (black) departure and (blue) arrival profiles.

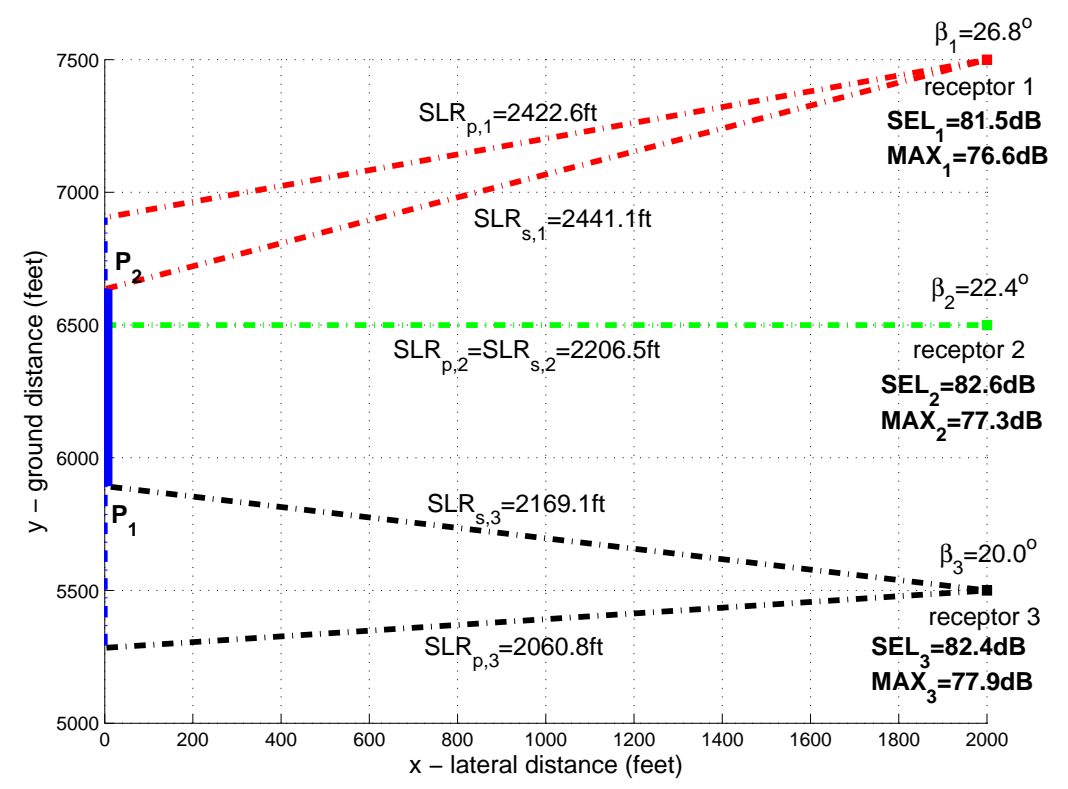

Figure 5: Exposure-based sound level and maximum sound level at observers (receptors) located (red) ahead, (green) aside, and (black) behind a departure aircraft route segment of an Airbus A340. Blue line represents aircraft route starting from $P_{1}$ to $P_{2} . S L R_{p}$ represents slant range (closest) distance to the flight path, $S L R_{s}$ represents slant range (closest) distance to the flight segment, and $\beta$ represents elevation angle.

Figure 6 shows the aircraft profile outputs from AEDT2b. The noise results using AIRNOISE developed in this paper are then compared with those using AEDT2b for validation. Note that neither AEDT2b nor AIRNOISE consider surface terrain. 


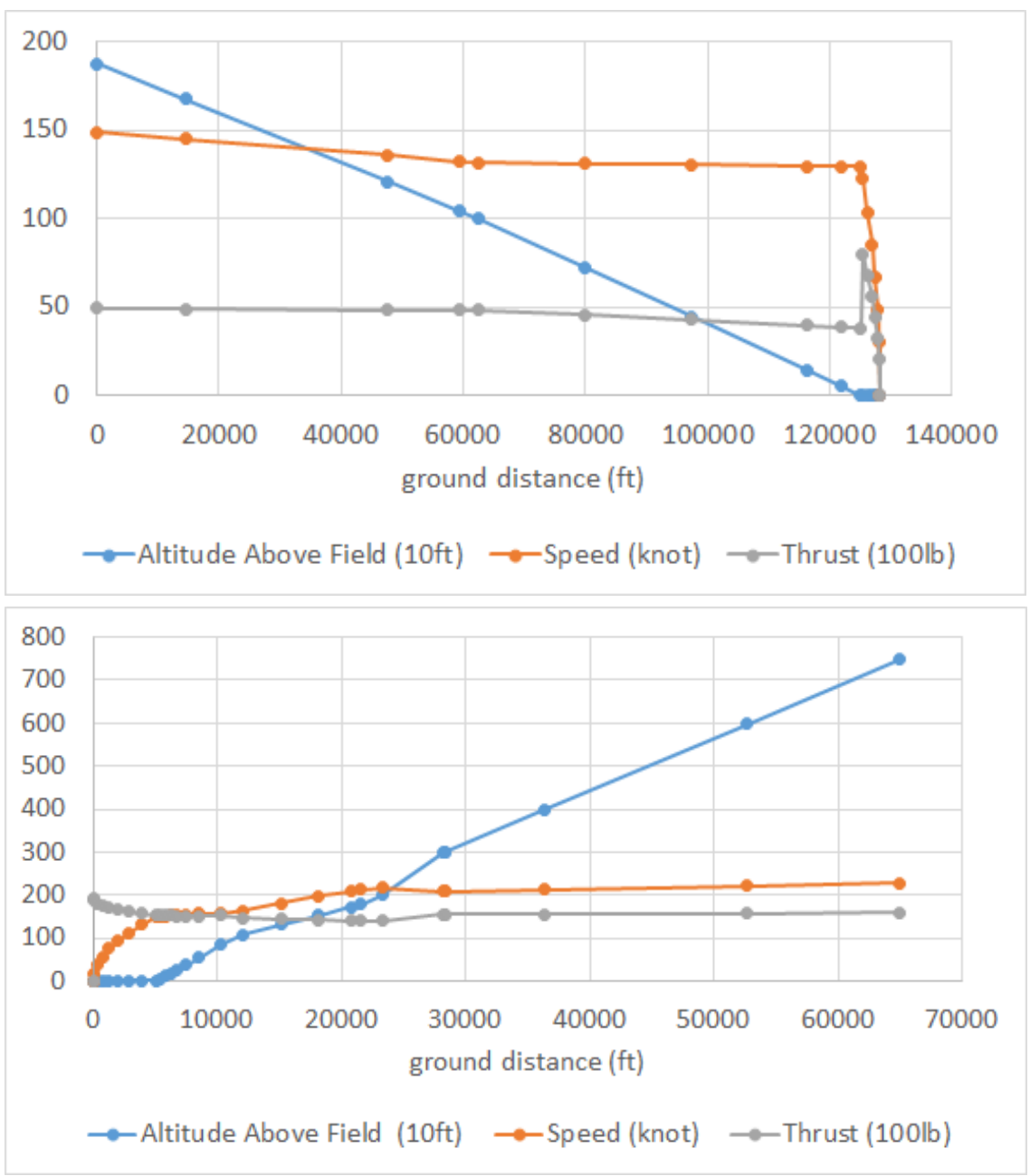

Figure 6: A Boeing 737-300 (top) arrival and (bottom) departure profiles at San Francisco International Airport

Figures 17 shows noise results using AEDT2b and AIRNOISE at a set of predefined grid points on the ground for the single arrival and departure flight operations in Fig. 6. Noise results from AEDT2b and AIRNOISE have the similar contour shape and size. Next, Figure 8 shows the differences by subtracting the noise values grid by grid between AEDT2b and AIRNOISE for quantitative assessment. The results from AIRNOISE shows good accuracy compared with the results from AEDT2b as the differences at almost all grid points are less than $2 \mathrm{~dB}$ (which is below the $3 \mathrm{~dB}$ threshold that is considered to be a noticeable change to the human ear), except in the area near the runway (left areas in Fig. 8) simply because noises resulting from the aircraft ground roll and taxi are not accounted for in AIRNOISE. More specifically, the average difference is $0.67 \mathrm{~dB}$ for the arrival profile and $1.0 \mathrm{~dB}$ for the departure profile excluding the area mainly impacted by aircraft ground operations. Finally, a common question is whether the noise difference at any grid point between AEDT2b and INM will increase proportionally with respect to the total number of flight arrival or departure operations. It can be proved that differences of total SEL at any grid point between AIRNOISE and AEDT2b for any $N \geq 1$ operations of the same flight profiles are unchanged with the proof provided in the appendix. This is important because it shows that accuracy of AIRNOISE compared with AEDT2b would not change no matter how many flight operations occur.

\section{Conclusion}

A simple aircraft noise computation tool, named AIRNOISE, is developed for aircraft noise-reduction route design. AIRNOISE is a simplified model of the commonly used aircraft noise assessment software INM 

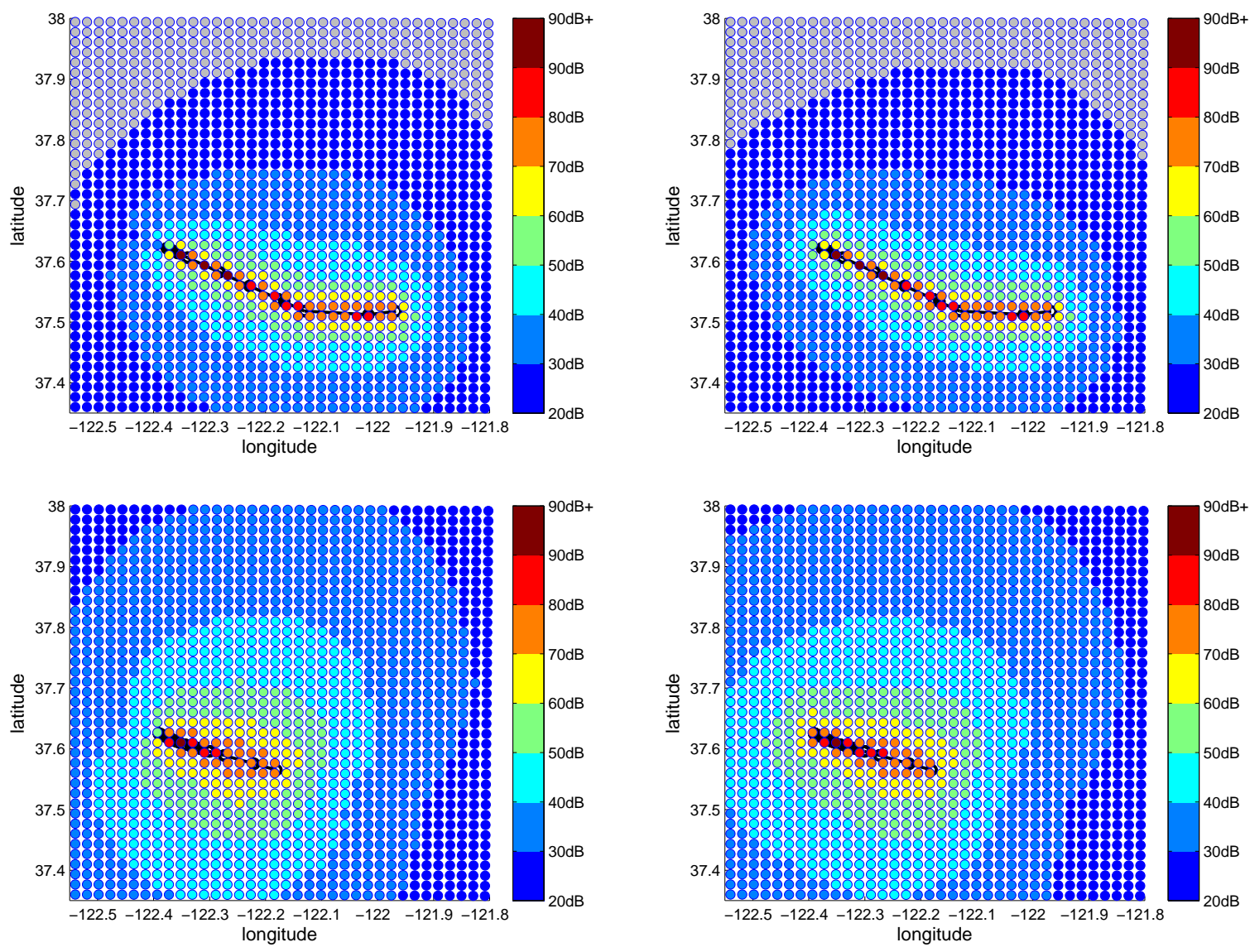

Figure 7: Sound exposure level (SEL) computed using AIRNOSIE and the FAA's AEDT2b for the flight profiles in Fig. 66 (top left) arrival using AIRNOISE, (top right) arrival using AEDT2b, (bottom left) departure using AIRNOISE, and (bottom right) departure using AEDT2b. The black line represents the aircraft route.
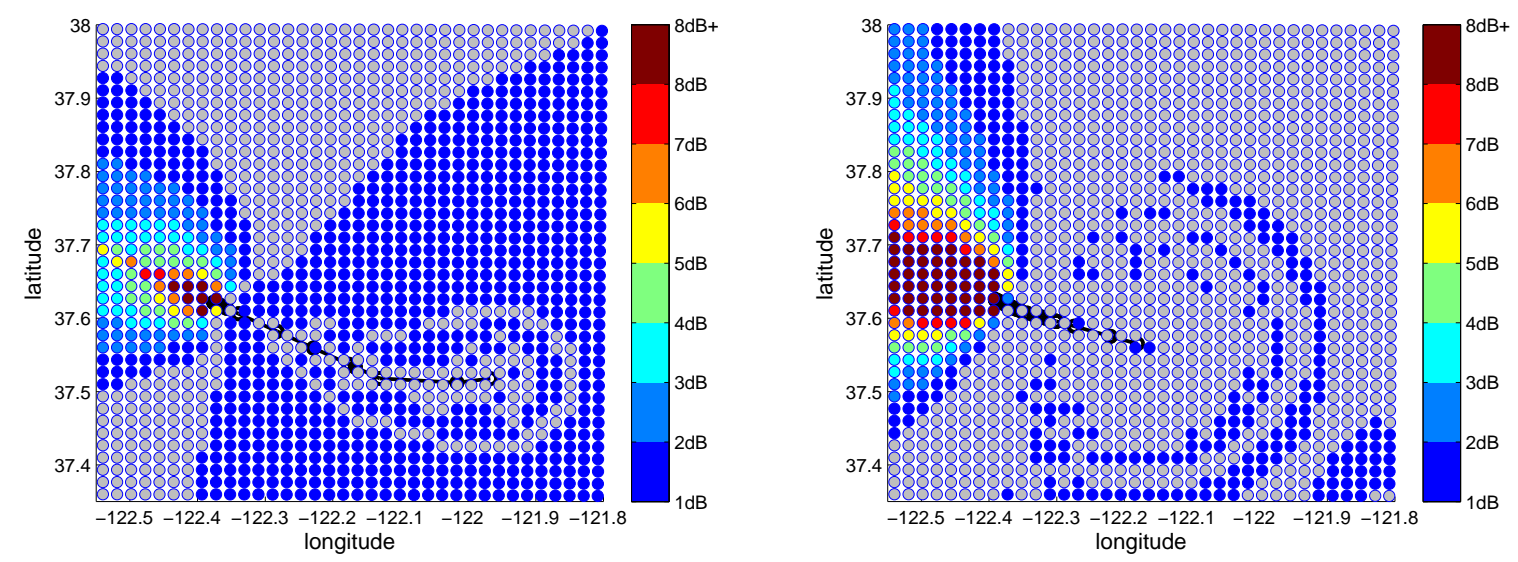

Figure 8: Sound exposure level (SEL) differences between AEDT2b and AIRNOISE for (left) arrival and (right) departure profiles in Fig. 6. The black line represents the aircraft route.

and AEDT without considering components related to terrain and atmosphere adjustments. AIRNOISE is computationally efficient and flexible to use for any customized flight profile inputs with access to intermediate results for iterative trajectory optimization. The tool can be integrated into flight simulation software 
as a noise computation module for real-time aircraft noise computation. The results from AIRNOISE are compared with those from the FAA's AEDT2b for single arrival and departure flight operations and showed reasonable accuracy. The maximum difference of noise results using AEDT2b and AIRNOISE is less than $2 \mathrm{~dB}$ and the average difference is less than $1 \mathrm{~dB}$, both of which are less than the $3 \mathrm{~dB}$ threshold that is considered to be a noticeable change by the human ear. We also showed that the accuracy does not change no matter how many flight operations are considered.

\section{Acknowledgments}

This paper is dedicated to the memory of Dr. Neil Y. Chen, who passed away on Monday, November 3rd, 2014. Dr. Chen was a respected air traffic management researcher, the focal point for international collaborations, and had initially led the autonomous traffic flow management research area. Dr. Chen received his Ph.D from UCLA in Mechanical and Aerospace Engineering in 2001. He is survived by his wife, Sue, and his two daughters, Stephanie and Sophia. We will sorely miss Neil, his friendship, and good humor.

\section{Appendix}

\section{V.A. Noise adjustment terms}

Equations of adjustment terms in Eqn. (1) are listed in this section. They are discussed in more details in INM7.0 Technical Manual! 12

1. Lateral attenuation adjustment:

$$
A D J_{L A}=-\left[E_{\text {engine }}(\phi)+\frac{G(l) \Lambda(\beta)}{10.86}\right]
$$

where $\phi=\beta+\epsilon$ is depression angle, $\beta$ is elevation angle from observer to aircraft route and $\epsilon$ is aircraft banking angle, $l$ is sideline distance, ie. perpendicular distance from observer to aircraft route ground projection, and

$$
\begin{array}{r}
E_{\text {engine }}(\phi)=10 \log _{10}\left(\frac{\left[0.0039 \cos ^{2}(\phi)+\sin ^{2}(\phi)\right]^{0.062}}{0.8786 \sin ^{2}(2 \phi)+\cos ^{2}(2 \phi)}\right) \\
G(l)= \begin{cases}11.83[1-\exp (-0.00274 l / 3.28)], & 0 \leq l \leq 3000 f t \\
10.86, & l>3000 f t\end{cases}
\end{array}
$$

and

$$
\Lambda(\beta)= \begin{cases}10.86, & \beta \leq 0 \\ 1.137-0.0229+9.72 \exp (-0.142 \beta), & \beta \leq 50^{\circ} \\ 0, & 50^{\circ}<\beta \leq 90^{\circ}\end{cases}
$$

2. Duration adjustment:

$$
A D J_{D U R}=10 \log (160 / V)
$$

where $V$ is aircraft speed.

3. Fraction adjustment:

$$
A D J_{N F}=10 \log F_{12}
$$

where $F_{12}$ is a function of not only geometric parameters but also NPD base noise for both exposurebased sound level and maximum-based sound level.

4. Directivity adjustment:

$$
A D J_{D I R}= \begin{cases}51.44-1.553 \theta+0.015147 \theta^{2}-0.000047173 \theta^{3}, & 90^{\circ} \leq \theta \leq 148.4^{\circ} \\ 339.18-2.5802 \theta-0.0045545 \theta^{2}+0.000044193 \theta^{3}, & 148.4^{\circ}<\theta \leq 180^{\circ}\end{cases}
$$

where $\theta$ is angle between line connecting observer with aircraft and aircraft ground-roll direction.

$$
8 \text { of } 9
$$




\section{V.B. Proof of noise difference accumulation}

Assume the total SEL at a grid point computed using AEDT2b is $L_{1, A E D T 2 b}$ for a single flight operation and $L_{N, A E D T 2 b}$ for $N \geq 1$ flight operations of the same flight profile. Similarly, $L_{1, A I R N O I S E}$ represents total SEL at the same grid point for the same single flight operation computed using AIRNOISE and $L_{N, A I R N O I S E}$ for $N$ operations. Let $d L_{1}=L_{1, A E D T 2 b}-L_{1, A I R N O I S E}$ represent noise difference computed using AEDT2b and AIRNOISE. Then we want to prove $d L_{N}=d L_{1}$.

Proof: Let $L^{(1)}$ represent SEL value for the 1-st single flight operation. $L_{1}=L^{(1)}$ by definition. Then SEL value of the $i$-th operation of the same flight profile $L^{(i)}=L^{(1)}=L_{1}$ for $i \leq N$ where $N$ is the total number of operations. The following equation can be derived using Eqn. (2):

$$
L_{N}=10 \log \left(N 10^{L_{1} / 10}\right)=10 \log (N)+L_{1}
$$

So $L_{N, A E D T}=10 \log (N)+L_{1, A E D T}$ and $L_{N, A I R N O I S E}=10 \log (N)+L_{1, N O I S E}$ using Eqn. (13). Finally,

$$
\begin{aligned}
d L_{N} & =L_{N, A E D T}-L_{N, A I R N O I S E} \\
& =10 \log (N)+L_{1, A E D T}-\left(10 \log (N)+L_{1, N O I S E}\right) \\
& =L_{1, A E D T}-L_{1, A I R N O I S E} \\
& =d L_{1}
\end{aligned}
$$

This completes the proof.

\section{References}

${ }^{1}$ Sridhar, B., Chen, N. Y., and Ng, H. K., "Simulation and Optimization Methods for Assessing the Impact of Aviation Operations on the Environment," 27th Congress of the International Council of the Aernoautical Sciences, Nice, France, 2010.

${ }^{2}$ Sridhar, B., Chen, N. Y., Ng, H. K., and Morando, A., "Modeling and Simulation of the Impact of Air Traffic Operations on the Environment," AIAA Modeling and Simulation Technologies Conference, Portland, OR, 2011.

${ }^{3}$ Sridhar, B., Chen, N. Y., and Ng, H. K., "Aircraft Trajectory Design Based on Reducing the Combined Effects of Carbon-Dioxide, Oxides of Nitrogen and Contrails," AIAA SciTech, National Harbor, Maryland, 2014.

${ }^{4}$ Schumann, U., "A contrail cirrus prediction model," International Conference on Transport, Atmosphere, and Climate, Vol. 5, 2012, pp. 543-580.

${ }^{5} \mathrm{Li}$, J., Kim, J., Sridhar, B., Chen, N., and Ng, H., "Modeling Aviation Induced Contrails and the Computation of Contrail Radiative Forcing Using Air Traffic Data," NASA Technical Report, 2015.

${ }^{6}$ Swift, H., "A Review of the Literature Related to Potential Health effects of Aircraft Noise," PARTNER Project 19 Final Report, 2010.

${ }^{7}$ Sizov, N., "Aviation Noise Impacts Research Roadmap 2011," Report No. DOT/FAA/AEE/2011-07, 2011.

${ }^{8}$ Cho, H., Azzam, M., Hansman, R. J., and Jensen, L. L., "Noise Analysis and Negotiation Tool for Terminal RNP Procedure Design," 2013 Aviation Technology, Integration, and Operations Conference, Los Angeles, CA, 2013.

${ }^{9} \mathrm{Ng}, \mathrm{H}$. K., Sridhar, B., Chen, N. Y., and Li, J., "Three-Dimensional Trajectory Design for Reducing Climate Impact of Trans-Atlantic Flights," 14th AIAA Aviation Technology, Integration and Operations Conference, Atlanta, GA, 2014.

${ }^{10}$ Gilmore, C., Barrett, S., Koo, J., and Wang, Q., "Temporal and spatial variability in the aviation NOx-related O3 impact," Environmental Research Letters B, Vol. 8, No. 3, 2013.

${ }^{11} \mathrm{SAE}$, "Procedure for the Calculation of Airplane Noise in the Vicinity of Airports," 1986.

${ }^{12}$ Boeker, E., Dinges, E., He, B., Fleming, G., Roof, C., Gerbi, P., Rapoza, A., and Hemann, J., "Integrated Noise Model (INM) Version 7.0 Technical Manual," 2008. 